\title{
黒鉛炉原子吸光法による硫黄中の微量金属成分の 直接定量
}

\author{
越野 幸広 ${ }^{\circledR}$, 生川 章*
}

(1990 年 9 月 25 日受理)

\begin{abstract}
黑鉛炉 AAS を使用した硫黄中の $\mathrm{ng} \mathrm{g}^{-1}$ レベルの $\mathrm{Al}, \mathrm{Fe}, \mathrm{Ni}, \mathrm{Cr}, \mathrm{Mn}$ 及び $\mathrm{Cu}$ の直接定量法を検討 した。硫黄試料は数 mg を固体のまま L'vov のプラットフォームを取り付けた黒鉛炉内に導入する. 硝酸を添加した後, 低温で徐々に加熱し, 硫黄をすべて揮散させた後, 分析元素のシグナルを得ること で硫黄によるマトリックス干渉が除去できた。そのため，検量線は分析金属元素を単に混合した標準溶 液を用いて作成できた。本法の再晲性は相対標準偏差として $10 \%$ 以内であり，分析值は硝酸-臭素分 解/ICP-AES 法の結果とよく一致した.
\end{abstract}

1 緒言

黑鉛炬 AAS は高感度な分析法として, 微量金属の定 量に幅広く用いられている. しかし，マトリックスの影 響を受けやすいため(1)2), 溶媒抽出法 ${ }^{334)}$, イオン交換 法(5)はな゙により目的元素を分離, 濃縮してから分析す る方法, マトリックスモディファイヤーを用いて AAS

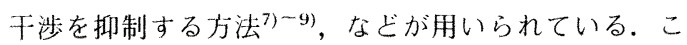
れらの方法は煩雑な操作が必要で, しかも, 用いる試 薬, 器具及び実験室の雾进気からの污染を受けやすい.

又, 近年, 試料を固体のまま黒鉛炉内に導入し, 目的元 素を值接定量する方法 ${ }^{(0)}$ が報告されているが，この方 法もなんらかの前処理, マトリックスモディファイヤー の添加などにより干渉を抑制している。

著者らは, 硫黄が低温で容易に揮散することに着目 し, 試料をL'vov のプラットフォームを取り付けた黒 鉛炬内に前処理なしで直接導入し, 硝酸を加え, 又は空 気を導人して $120 \sim 500^{\circ} \mathrm{C}$ の間で昇温することで硫黄の みを揮散させた後，目的元素を原子化させて定量する方 法を試みたところ, 数 $\mathrm{mg}$ の試料を用いて, $\mathrm{ng} \mathrm{g}^{-1} レ$ ベルの $\mathrm{Al}, \mathrm{Fe}, \mathrm{Ni}, \mathrm{Cr}, \mathrm{Mn}$ 及び $\mathrm{Cu}$ を迅速に精度よく定 量できたので報告する.

* 日本ガイシ(株)研究開発本部第 1 研究所 : 467 愛知県 名古屋市瑞穂区須由町 2-56
2 実験

\section{$2 \cdot 1$ 装 置}

黑鉛炉原子吸光装置は Perkin-Elmer 製 Zeeman バッ クグラウンド補正機構付き Z5100 型に同社製の ZHGA-600 グラファイトアトマイザー及び AS60 オー トサンプラーを装着して使用した。昇温条件の設定，標 準溶液の注入などは同社製の 7700 コンピューターを用 いてコントロールし, 吸光度はすべてピーク面積で表示 させた. 光源には同社製のコーディッド中空陰極ランプ を，黒鉛炉及び L'vov のプラットフォームはすべてパ イロコーティングされたものを用いた. ICP 発光分光 装置にはセイコ一電子工業製 SPS-1100 型を，化学はか りには METTLER 製 AE-163 を用いた。

\section{$2 \cdot 2$ 試薬及び器具}

硫黄試料: 高純度 $(99.9999 \%)$, 試薬特級（結晶）及 び工業用グレードの 3 種を用いた。

合成硫黄試料: 試薬特級硫黄 $20 \mathrm{~g}$ を白金血にとり, クリーンルームに設犆されたクリーンドラフト内で $\mathrm{Al}$, $\mathrm{Fe}, \mathrm{Ni}, \mathrm{Cr}, \mathrm{Mn}$ 及び $\mathrm{Cu}$ をそれぞれ $2 \mu \mathrm{g}$ 添加して水約 $10 \mathrm{ml}$ を加えてかき混ぜた後, ドライヤーを用いて水分 を蒸発させ，ホットプレート上 $120^{\circ} \mathrm{C}$ で硫黄を溶融状 態として 30 分間保持する. 放冷後, 高純度アルミナ乳 鉢に移して粉砕し，デシケーター中に保存した。アルミ ナ乳鉢を用いたため $\mathrm{Al}$ が混入したが，本法の正確さを 確かめるために調製した試料であり，そのまま使用し 
た。

金属標準溶液 : $\mathrm{Al}, \mathrm{Fe}, \mathrm{Ni}, \mathrm{Cr}, \mathrm{Mn}, \mathrm{Cu}$ のすべてにつ いて高純度金属を用い, 塩酸 $(1+1)$, 硝酸 $(1+1)$ あ るいはこの混酸を用いて加熱溶解する. 水で希釈して $0.1 \mathrm{M}$ の酸性としてテフロン瓶中に保存し, $1 \mathrm{mg} \mathrm{ml}^{-1}$ の原液を調製した。これを使用の都度, 適宜希釈して用 いた。

塩酸及び硝酸 : Cica-Merck 製超高純度品をそのまま 使用した.

水: 蒸留水を Milli- $Q$ 水製造システムに通して使用し た。

その他の試薬 : 市販特級品をそのまま使用した.

\section{$2 \cdot 3$ 定量操作}

硫黄試料約 $100 \mathrm{mg}$ を薬包紙にとり, マイクロピペッ ト用チップと共に化学はかりに載せ， $0.1 \mathrm{mg}$ のけたま で正確に読み取った後, マイクロピペット用チップを L'vov のプラットフォームを取り付けた黒鉛炬内に挿入 し，次いで硫黄 1 5 mg をステンレス製の薬さじを用 いて炬内に導入する，チップを抜き，薬包紙と共に再び 重量を測定し，もとの重量との差より炉内に導入した硫 黄量を算出しておく.オートサンプラーを用い, $0.2 \%$ 硝酸 $20 \mu \mathrm{l}$ を注入後, Table 1 に示す条件に従って AAS 測定を行った．得られた吸光度より目的金属元素量を算 出し, 導入量で除して試料中の含有率を求めた。硫黄は 吸湿性がほとんどなく，大気中，化学はかり上に数時間 放置しておいても重量に変化はなかった，又，薬さじに 付着することもなく, $\mathrm{Fe}, \mathrm{Ni}, \mathrm{Cr}$ などの污染もなかっ
た。

検量線は金属標準溶液を適宜希釈し， $0.2 \%$ 硝酸酸性 として Table 1 の条件に従って作成した.

なお，これらの実験及び測定はすべてクリーンルーム 内で行った.

\section{3 結果と考察}

\section{$3 \cdot 1$ 測定条件}

硫黄を直接黒鉛炬に導入し，目的金属元素を定量する ための测定条件を Table 1 に示した。硫黄は融点 $119.0^{\circ} \mathrm{C}$, 沸点 $444.6^{\circ} \mathrm{C}$ であり，低温で容易に除去でき る. 試料として黒鉛炉内に導入した硫黄に硝酸を添加 し， Ar 又は空気雾井気中で $120 \sim 500^{\circ} \mathrm{C}$ に加熱するこ とで硫黄のみを揮散除去できた。 Table 1 の Pretreating condition 1〜4 はその昇温条件である. 硝酸の添加は目 的金属元素の酸化の促進に有用と考えられるが， Ni 以 外の元素を定量する場合には単に空気䨌囲気中で加熱し ても同様の結果が得られた。この条件を用いて高純度硫 黄 $3.0 \mathrm{mg}$ に $\mathrm{Al} 400 \mathrm{pg}$ を添加して $2 \cdot 3$ に示した操作に 従って原子化させた際の面積吸光度一時間プロフィルを Fig. 1 に示す. Fig. 1 で高さの違いは硫黄中に含まれる 不純物の $\mathrm{Al}$ によるものであり，プロフィルは $\mathrm{Al}$ のみ を原子化させた場合と同じ形状であった。 200 $500^{\circ} \mathrm{C}$ の保持時間を各段階とも $60 \mathrm{~s}$ に増加してもプロフィル に変化はなく, 又, $200 \sim 500^{\circ} \mathrm{C}$ における炬内の雲囲気 を Ar から空気に変えてもプロフィルに変化はなかっ た. 更に, マトリックスモディファイヤーとして Mg$\left(\mathrm{NO}_{3}\right)_{2}, \mathrm{NH}_{4} \mathrm{H}_{2}\left(\mathrm{PO}_{4}\right)$ 及び $\left(\mathrm{NH}_{4}\right)_{2} \mathrm{HPO}_{4}$ の $0.2 \%$ 水

Table 1 Operating conditions for graphite furnace AAS

\begin{tabular}{|c|c|c|c|c|c|c|}
\hline Condition & $\mathrm{Al}$ & $\mathrm{Fe}$ & $\mathrm{Ni}$ & $\mathrm{Cr}$ & $\mathrm{Mn}$ & $\mathrm{Cu}$ \\
\hline Wavelength $(\mathrm{nm})$ & 309.3 & 248.3 & 232.0 & 357.9 & 279.5 & 324.8 \\
\hline Slit width (nm) & 0.7 & 0.2 & 0.2 & 0.7 & 0.2 & 0.7 \\
\hline Lamp current $(\mathrm{mA})$ & 25 & 30 & 25 & 25 & 20 & 15 \\
\hline Pretreating condition $1\left({ }^{\circ} \mathrm{C}\right)$ & 120 & 120 & 120 & 120 & 120 & 120 \\
\hline$(\mathrm{ramp} / \mathrm{s}-\mathrm{hold} / \mathrm{s})$ & $(1-40)$ & $(1-40)$ & $(1-40)$ & $(1-40)$ & $(1-40)$ & $(1-40)$ \\
\hline Pretreating condition $2\left({ }^{\circ} \mathrm{C}\right)$ & 200 & 200 & $200^{\dagger}$ & 200 & 200 & 200 \\
\hline$(\mathrm{ramp} / \mathrm{s}-$ hold$/ \mathrm{s})$ & $(10-30)$ & $(10-30)$ & $(10-30)$ & $(10-30)$ & $(10-30)$ & $(10-30)$ \\
\hline Pretreating condition $3\left({ }^{\circ} \mathrm{C}\right)$ & 300 & 300 & $300^{\dagger}$ & 300 & 300 & 300 \\
\hline$(\mathrm{ramp} / \mathrm{s}-\mathrm{hold} / \mathrm{s})$ & $(5-30)$ & $(5-30)$ & $(5-30)$ & $(5-30)$ & $(5-30)$ & $(5-30)$ \\
\hline Pretreating condition $4\left({ }^{\circ} \mathrm{C}\right)$ & 500 & 500 & $500^{\dagger}$ & 500 & 500 & 500 \\
\hline (ramp/s-hold/s) & $(5-20)$ & $(5-20)$ & $(5-20)$ & $(5-20)$ & $(5-20)$ & $(5-20)$ \\
\hline Ashnig condition $\left({ }^{\circ} \mathrm{C}\right)$ & 1500 & 1400 & 1400 & 1650 & 1500 & 1000 \\
\hline$(\mathrm{ramp} / \mathrm{s}-\mathrm{hold} / \mathrm{s})$ & $(10-20)$ & $(10-20)$ & $(10-20)$ & $(10-20)$ & $(10-20)$ & $(10-20)$ \\
\hline Atomizing condition & 2600 & 2500 & 2500 & 2500 & 2600 & 2300 \\
\hline (ramp/s-hold/s) & $(0-5)$ & $(0-5)$ & $(0-5)$ & $(0-5)$ & $(0-5)$ & $(0-5)$ \\
\hline
\end{tabular}

Ar flow rate : $300 \mathrm{ml} \mathrm{min}^{-1}$. $†$ Air was used instead of Ar. 


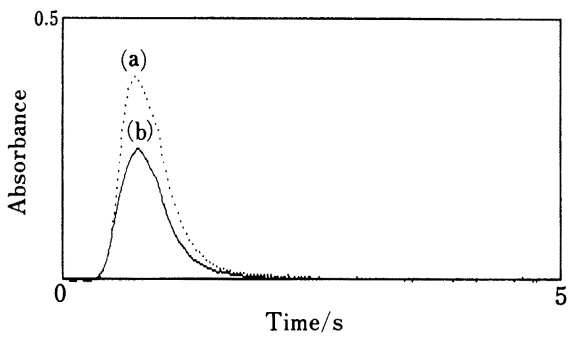

Fig. 1 Absorption spectra of $\mathrm{Al}$ (a) $(\mathrm{Al} 400 \mathrm{pg})+($ sulfur $3.0 \mathrm{mg})$; (b) $\mathrm{Al} 400 \mathrm{pg}$

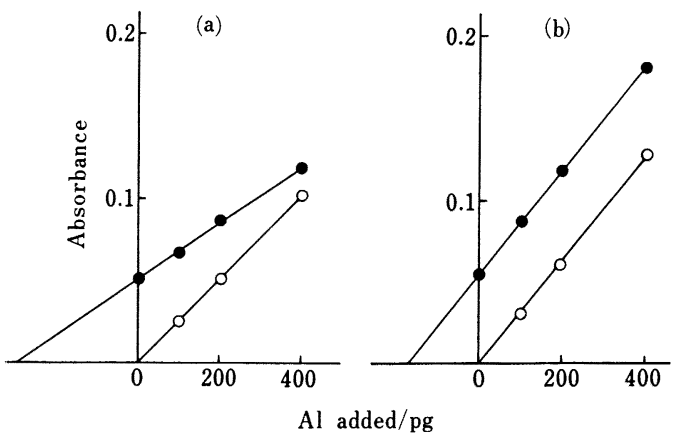

Fig. 2 Effect of graphite tube type on determination

(a) : ordinary tube; (b) : L'vov platform tube; $\bigcirc$ : standard solution; : (standard soultion) + (sulfur)

溶液 $20 \mu \mathrm{l}$ を添加してもプロフィルに変化はなかった. $\mathrm{Fe}, \mathrm{Ni}, \mathrm{Cr}, \mathrm{Mn}$ 及び Cu についても, Table 1 の条件に 従って $\mathrm{Al}$ と同様の実験を行った結果, マトリックスモ ディファイヤーなしで良好なプロフィルが得られること が分かった．従って，もし硫黄が残存しても，マトリッ クスの影響はないと考えられた。

\section{$3 \cdot 2$ 検量線と定量下限}

$3 \cdot 1$ より $500^{\circ} \mathrm{C}$ までの加熱で硫黄のみを除去できる と考えられたので, 金属標準溶液を単に希釈して作成し た検量線が適用できるか否かを検討した． Al 0 20 ng $\mathrm{ml}^{-1}$ の $0.2 \%$ 硝酸酸性溶液 $20 \mu \mathrm{l}$ を黒鉛炉内に注入し て Table 1 に示す条件下で AAS 測定を行って得た吸光 度と硫黄 $3.0 \mathrm{mg}$ を黒鉛炉内に導入後, 同様に $\mathrm{Al}$ を添 加して得た吸光度をプロットした結果を Fig. 2 に示 す.プラットフォームを使用しない黒鉛炉では固体硫黄 を添加すると直線の傾きが低下する傾向が見られた。こ れは黒鉛炉壁と炉内の温度が平衡に達する前に原子化が
Table 2 Lower determination $\operatorname{limit}^{\dagger}\left(\mathrm{ng} \mathrm{g}^{-1}\right)$

\begin{tabular}{lr}
\hline $\mathrm{Al}$ & 5 \\
$\mathrm{Fe}$ & 10 \\
$\mathrm{Ni}$ & 10 \\
$\mathrm{Cr}$ & 10 \\
$\mathrm{Nn}$ & 5 \\
$\mathrm{Cu}$ & 10 \\
\hline
\end{tabular}

$\dagger$ Based on $5 \mathrm{mg}$ of sulfur sample.

Table 3 Determination of trace metals in sulfur samples

\begin{tabular}{lrrrrc}
\hline \multicolumn{5}{c}{ Concentration/ng g } \\
\hline $\mathrm{Al}$ & $\mathrm{Fe}$ & $\mathrm{Ni}$ & $\mathrm{Cr}$ & $\mathrm{Mn}$ & $\mathrm{Cu}$ \\
\hline \multicolumn{2}{l}{ High purity } \\
60 & 60 & $<10$ & $<10$ & 20 & 40 \\
$(5.8)^{\dagger}$ & $(6.2)$ & $(-)$ & $(-)$ & $(6.4)$ & $(6.5)$ \\
Guaranteed & & & & \\
30 & 50 & 20 & 10 & 10 & 20 \\
$(8.6)$ & $(7.1)$ & $(7.2)$ & $(5.6)$ & $(5.7)$ & $(3.2)$ \\
Industrial & & & & \\
1880 & 5400 & 70 & 280 & 170 & 80 \\
$(7.4)$ & $(7.8)$ & $(6.1)$ & $(5.9)$ & $(8.3)$ & $(9.1)$ \\
\hline
\end{tabular}

$\dagger$ Relative standard deviation of five determinations

起こるためと考えられる.これに対し L'vov のプラッ トフォームを用いると炉壁と炉内の温度が平衡に達して から原子化が起こるので $\mathrm{Al}$ の揮散もなく, 高い吸光度 が得られる. 硫黄を添加した場合でも検量線こう配の平 行関係が成立し，金属標準溶液の検量線を用いて定量可 能なことが判明した. $\mathrm{Fe}, \mathrm{Ni}, \mathrm{Cr}, \mathrm{Mn}$ 及び $\mathrm{Cu}$ について も同様の関係が成立することを確認した. $5 \mathrm{mg}$ の硫黄 を黒鉛炉内に導入し，2.3に示した操作に従った場合の 定量下限を Table 2 に示す.これより $\mathrm{Al}, \mathrm{Mn}$ は $5 \mathrm{ng}$ $\mathrm{g}^{-1}, \mathrm{Fe}, \mathrm{Ni}, \mathrm{Cr}$ 及び $\mathrm{Cu}$ は $10 \mathrm{ng} \mathrm{g}^{-1}$ 以上であれば定量 可能であった，試料導入量を増せば更に，定量下限を下 げることも可能である. 本法におけるから試験值は $0.2 \%$ 硝酸 $20 \mu \mathrm{l}$ を黒鉛炉に注入して Table 1 の条件に 従って吸光度を測定したが，黒鉛炉のから焼きを10 回 以上行っておけば，どの金属元素の測定においても無視 できるものであった.

\section{$3 \cdot 3$ 実際試料の分析}

本法により純度の異なる 3 種の硫黄を分析した結果 を Table 3 に示す. 数十 $\mathrm{ng} \mathrm{g}^{-1}$ 程度の金属を相対標準 偏差 $10 \%$ 以内の精度で定量可能であった. 
Table 4 Comparison of analytical results obtained by proposed and ICP-AES methods

\begin{tabular}{cccccc}
\hline \multicolumn{5}{c}{ Concentration/ng g } \\
\hline $\mathrm{Al}$ & $\mathrm{Fe}$ & $\mathrm{Ni}$ & $\mathrm{Cr}$ & $\mathrm{Mn}$ & $\mathrm{Cu}$ \\
\hline $\begin{array}{l}\text { Proposed } \\
5900\end{array}$ & 140 & 90 & 110 & 100 & 130 \\
$(5.3)^{\dagger}$ & $(6.9)$ & $(8.6)$ & $(7.2)$ & $(8.3)$ & $(6.6)$ \\
$\begin{array}{l}\mathrm{ICP}-\mathrm{AES} \\
5900\end{array}$ & 250 & 90 & 110 & 90 & 110 \\
\hline
\end{tabular}

$\dagger$ Relative standard deviation of five determinations

本法による分析の正確さを確かめるために以下の実験 を行った。合成硫黄試料 $10 \mathrm{~g}$ をパイレックス製のビー カーにとり, 硝酸 $80 \mathrm{ml}$ と臭素約 $20 \mathrm{ml}$ で分解して硫 酸イオンとした後，砂皿上で蒸発乾固する. 残留物を $0.1 \mathrm{M}$ 硝酸に溶解し, $10 \mathrm{ml}$ 定容として各金属元素を測 定した. Table 4 に本法と ICP-AES 法が Fe を除いて よく一致する分析結果を与えることを示した。 ICP-AES 法で Fe の定量值が本法より高いのは試料分 解時に硝酸と臭素を多量に用いたため試薬中の不純物 $\mathrm{Fe}$ に起因すると考えられる。本法は ICP-AES 法と比 較し，分析時間が半分で，しかも一けた低い濃度まで定 量が可能であった。

以上，黒鉛炬 $\mathrm{AAS}$ を用いて硫黄中の $\mathrm{Al}, \mathrm{Fe}, \mathrm{Ni}, \mathrm{Cr}$,
$\mathrm{Mn}$ 及び $\mathrm{Cu}$ を直接定量した. 本法の特徵は前処理なし で試料となる硫黄を固体のまま黒鉛炬に導入し, 120 500 ${ }^{\circ} \mathrm{C}$ の低温で硫黄のみを容易に除去できる点に ある.これにより, 試薬などからの污染を最小限によど め, 数 $\mathrm{mg}$ の試料を用いて, 簡易, 迅速かつ精度よく黑 鉛炬 AAS 測定することができた。 又，本法は有機物中 の微量金属元素の直接定量などにも忍用が可能であるも のと考えられ，污染の少ない迅速分析法として今後，多 方面での応用が期待される.

\section{文献}

1) B. Welz, G. Schlemmer, J. R. Mudakav: Anal. Chem., 60, 2567 (1988).

2) R. E. Styrgeon, S. S. Berman, A. Desauiniers, D. S. Russell : Anal. Chem., 51, 2364 (1979).

3) Y. Shinjo, T. Shimizu, T. Tsunoda: Anal. Sci., 5, 65 (1989).

4）上田一正, 北原 俊, 久保勝寿, 川本善-：分析化 学, 36, 728 (1987).

5) R. Kobayashi, K. Imaizumi : Anal. Sci., 5, 61 (1989).

6）清水得夫, 市川兼司, 伊澤雅幸, 四条好雄: 分析化 学, 38, 201 (1989).

7）多賀光彦, 桜田 修, 高橋英明: 分析化学, 37, 164 (1988).

8）桜田 修, 高橋英明, 多賀光彦: 分析化学, 38, 407 (1989).

9) 松崎浩司, 吉野 隆: 分析化学, 35,931 (1986).

10) S. Backman, R. W. Karlsson : Analyst (London), 104, 1617 (1979).

Direct determination of trace metal elements in sulfur by graphite furnace AAS. Yukihiro Koshino and Akira Narukawa (Analysis \& Properities Research Laboratory, Corporate Research and Development Group, NGK Insulators, Ltd., 2-56, Suda-cho, Mizuho-ku, Nagoya-shi, Aichi 467)

A simple method without matrix interference for the direct determination of $\mathrm{Al}, \mathrm{Fe}$, $\mathrm{Ni}, \mathrm{Cr}, \mathrm{Mn}$ and $\mathrm{Cu}$ in sulfur by graphite furnace AAS has been developed. Effect of sulfur matrix could be removed easily by preheating furnace at $120 \sim 500^{\circ} \mathrm{C}$, and integrated absorbance-time profile with small background absorption was obtained. Furthermore, metal standard solutions could be used as calibration standards by using pyro-coated L'vov platform graphite tube. This proposed method was applied to the rapid determination of the trace metal elements in sulfur samples, using 1 $\sim \mathrm{mg}$ sample weight. The relative standard deviations of analytical values were within $10 \%$. Accuracy of this method was checked by the $\mathrm{HNO}_{3}-\mathrm{Br}_{2}$ decomposition/ICP-AES method.

(Received September 25, 1990)

\section{Keyword phrases}

direct determination of $\mathrm{Al}, \mathrm{Fe}, \mathrm{Ni}, \mathrm{Gr}, \mathrm{Mn}$ and $\mathrm{Cu}$; graphite furnace AAS; L'vov platform; trace metals in sulfur. 